\title{
MENENTUKAN FREKUENSI SPEKTRUM ELEKTROMAGNETIK PADA AKTIVITAS PEMBELAJARAN FISIKA
}

\author{
Ayuni Nuraeni ${ }^{1 * a}$, Ulfa Hanifa Azzahra ${ }^{1 * \mathrm{~b}}, \mathrm{Nana}^{2}$ \\ ${ }^{1}$ Mahasiswa Jurusan Pendidikan Fisika Universitas Siliwangi \\ ${ }^{2}$ Dosen Jurusan Pendidikan Fisika Universitas Siliwangi \\ Tasikmalaya Jawa Barat Indonesia 46115
}

\begin{abstract}
Abstrak
Penelitian ini bertujuan untuk menentukan frekuensi spektrum elektromagnetik dalam aktivitas pembelajaran fisika. Dan didukung dengan penerapannya secara nyata dalam teknologi. Metode penelitian yang digunakan adalah metode eksperimen yang didukung oleh studi literatur yang bersumber dari buku, internet, jurnal dan sebagainya serta praktikum virtual dengan menggunakan website. Melalui persamaan matematis dan hasil penelitian bahwa frekuensi spektrum elektromagnetik berbanding terbalik dengan panjang gelombangnya. Penerapan nya bahkan begitu nyata dan familiar disekitar kita seperti Bluetooth, pemancar TV dan masih banyak lagi. Dalam penggunaan teknologi yang memanfaatkan radiasi elektromagnetik perlu dipehatikan karena jika kurang bijaksana dan kurangnya pengetahuan dapat menimbulkan akibat yang besar seperti larangan mengaktifkan ponsel dalam pesawat.
\end{abstract}

Kata Kunci: Spektrum elektromagnetik, Panjang gelombang, Frekuensi

\section{Pendahuluan}

Fisika adalah salah satu ilmu yang paling dasar dari ilmu pengetahuan. Fisika merupakan dasar dari ilmu rekayasa dan teknologi. Fisika adalah ilmu yang bersifat empiris, artinya setiap hal yang dipelajari dalam fisika didasarkan pada hasil pengamatan tentang gejala alam dan gejala-gejalanya (Sutarto, 2005). Fisika sangat erat kaitanya dengan teknologi yang sekarang banyak digunakan dalam kehidupan. Akan tetapi, banyak orang yang tak menyadari dan hanya menggunakannya. Bahkan dikalangan peserta ddik atau pelajar mengganggap fisika identik dengan rumus dan perhitungan yang rumit. Sehingga tingkat pemahaman peserta didik terhadap fisika terhitung rendah. 
Fisika di era saat ini dapat dibawakan dengan cara yang lebih mudah dipahami dan efektif baik secara fenomena yang berada disekitar dan digital. Sehingga untuk meningkatkan pemahaman peserta didik diperlukan pembelajaran yang kreatif dan dapat dipelajari secara nyata dilapangan. Tantangan baru dinamika kehidupan yang makin kompleks menuntut aktivitas pembelajaran bukan sekedar mengulang fakta dan fenomena keseharian yang dapat diduga melainkan mampu menjangkau pada situasi baru yang tak terduga. Dengan dukungan kemajuan teknologi dan seni, pembelajaran diharapkan mendorong kemampuan berpikir siswa hingga situasi baru yang tak terduga (Nana, 2018). Karena sebagian besar pembelajaran dalam fisika memilki variasi yang didasarkan pada kognitif, afektif dan psikomotor (Nana, 2014). Sehingga pembelajaran fisika haruslah mengajarkan anak untuk dapat memahami situsi dan mengasah ketajaman intuisi agar kogtinif, afektif dan psikomotornya terus berkembang.

Fisika yang telah menjalar diberbagai bidang kehidupan dapat dijadikan permasalahan yang dapat diidentifikasi oleh peserta didik. Sehingga peserta didik terlatih dalam mengenali situasi dan persoalan materi fisika yang telah mereka pelajari disekitarnya serta mendorong kemampuan berpikir siswa. Salah satu materi fisika adalah radiasi elektromagnetik yang dipelajari di kelas 12 SMA/MA. Radiasi elektromagnetik disebabkan dari gelombang elektromagnetik. Gelombang elektromagnetik itu sendiri merupakan kombinasi medan listrik dan medan magnet yang berosilasi dengan dua arah getaran yang saling tegak lurus dan termasuk gelombang transversal yang merambat tanpa medium dengan membawa energi dari satu tempat ke tempat lainya. Gelombang elektromagnetik memiliki rentang tertentu berdasarkan panjang gelombang dan frekuensinya, yang biasa disebut spektrum elektromagnetik. Spektrum elektromagnetik terdiri dari geombang radio, gelombang mikro, infremerah, cahaya tampak, sinar ultraviolet (UV), sinar X dan sinar gamma dengan besar frekuensi dan panjang gelombang yang berbeda. Energi elektromagnetik dipancarkan, atau dilepaskan, oleh semua masa di alam semesta pada level yang berbeda beda. Semakin tinggi level energi dalam suatu sumber energi, semakin rendah panjang gelombang dari energi yang dihasilkan, dan semakin tinggi frekuensinya. Perbedaan karakteristik energi gelombang digunakan untuk mengelompokkan energi elektromagnetik (Timor, 2016).

Beberapa nama spektrum elektromagnetik seperti sinar X, sinar Ultraviolet (UV) dan inframerah terdengar familiar, sedangkan yang lainnya sedikit terdengar asing. karena spektrum elektromagnetik ini sulit untuk dilihat secara langsung, kita hanya dapat mengetahuinya dari teknologi-teknologi yang memanfaatkan spektrum elektromagnetik 
seperti sinar $\mathrm{X}$ yang dikenal dengan rontgen untuk memeriksa organ dalam manusia. Oleh sebab itu, agar lebih dapat memahami konsep materi radiasi elektromagnetik dengan cara memelajari penerapannya dan mentukan gelombang elektromagnetik yang digunakan sesuai dengan panjang gelombang dan frekuensinya. Banyak sekali spektrum elektromagnetik yang digunakan dalam teknlogi seperti bluetooth untuk transmisi data, smartphone untuk komunikasi dan akses internet serta yang lainnya. Bahkan terdapat banyak simulasi online yang dapat digunakan untuk memperdalam pemahaman konsep materi radiasi elektromagnetik. Pemahaman konsep merupakan suatu aspek yang sangat penting dalam pembelajaran, karena dengan memahami konsep siswa dapat mengembangkan kemampuannya dalam setiap materi pelajaran (Fitriyah, 2018).

\section{Metode Penelitian}

Penelitian dilakukan dengan menggunakan metode eksperimen yang didukung oleh studi literatur yang bersumber dari jurnal, buku dan internet. Eksperimen dilakukan dengan menggunakan alamat website yang dikembangkan oleh Dr. Byron Philhour dalam cK-12 Exploration Series yaitu,

\section{https://uc.xyz/QqtpB?pub=link}

Eksperimen dapat menggunakan smartphone, komputer atau laptop yang telah tersambung dengan koneksi internet.

\section{Hasil Penelitian dan Pembahasan}

Penelitian ini menggunakan alamat website yang menampilkan simulasi gelombang elektromagnetik dengan nilai panjang gelombang yang dapat diubah-ubah untuk menentukan nilai frekuensi dan menyesuaikan hasil perhitungan untuk menentukan frekuensi dengan rentang spektrum elektromagnetik.

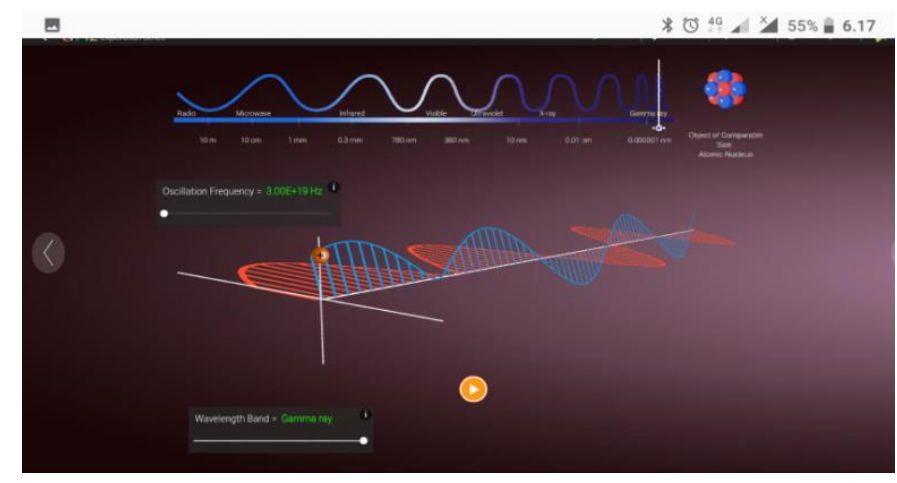


Gambar 1. Simulasi gelombang elektromagnetik

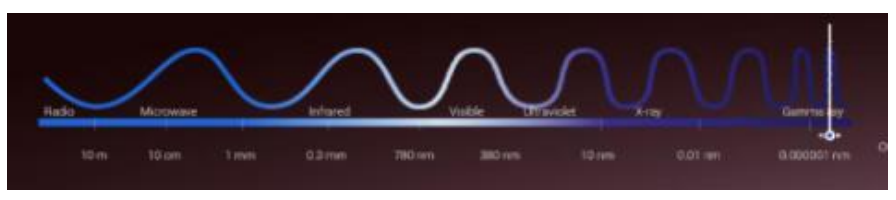

Gambar 2. Rentang panjang gelombang yang dapat diubah-ubah

Secara umum, panjang gelombang, frekuensi dan kecepatan perambatan gelombang elektromagnetik memenuhi persamaan berikut,

$$
c=\lambda \cdot f
$$

$c=$ kecepata gelombang elektromagnetik $/$ kecepatan cahaya $3 \times 10^{8} \mathrm{~m} / \mathrm{s}$

$\lambda=$ panjang gelombang $(\mathrm{m})$

$f=$ frekuensi (Hertz)

Maka persamaan untuk mencari frekuensi adalah,

$$
f=\frac{c}{\lambda}
$$

yang berarti,

$$
f \approx \frac{1}{\lambda}
$$

\begin{tabular}{|c|c|c|}
\hline $\begin{array}{c}\text { Spektrum } \\
\text { Elektromag } \\
\text { netik }\end{array}$ & Frekuensi & $\begin{array}{c}\text { Panjang } \\
\text { Gelomb } \\
\text { ang }\end{array}$ \\
\hline \multirow[t]{3}{*}{ Gamma ray } & $\begin{array}{l}3 \times 10^{8} / 55.8 \\
\times 10^{-15} \mathrm{~m}= \\
5.3 \times 10^{21} \mathrm{~Hz}\end{array}$ & $\begin{array}{c}1 \times \\
10^{-15} \mathrm{~m}\end{array}$ \\
\hline & $\begin{array}{l}3 \times \\
10^{8} / 57.0 \times \\
10^{-15} \mathrm{~m}= \\
5.2 \times 10^{21} \mathrm{~Hz}\end{array}$ & $\begin{array}{c}1 \times \\
10^{-15} \mathrm{~m}\end{array}$ \\
\hline & $\begin{array}{l}3 \times \\
10^{8} / 58.7 \times \\
10^{-15} \mathrm{~m}= \\
5.1 \times 10^{21} \mathrm{~Hz}\end{array}$ & $\begin{array}{c}1 \times \\
10^{-15} \mathrm{~m}\end{array}$ \\
\hline
\end{tabular}

Tabel 1. Data hasil percobaan 


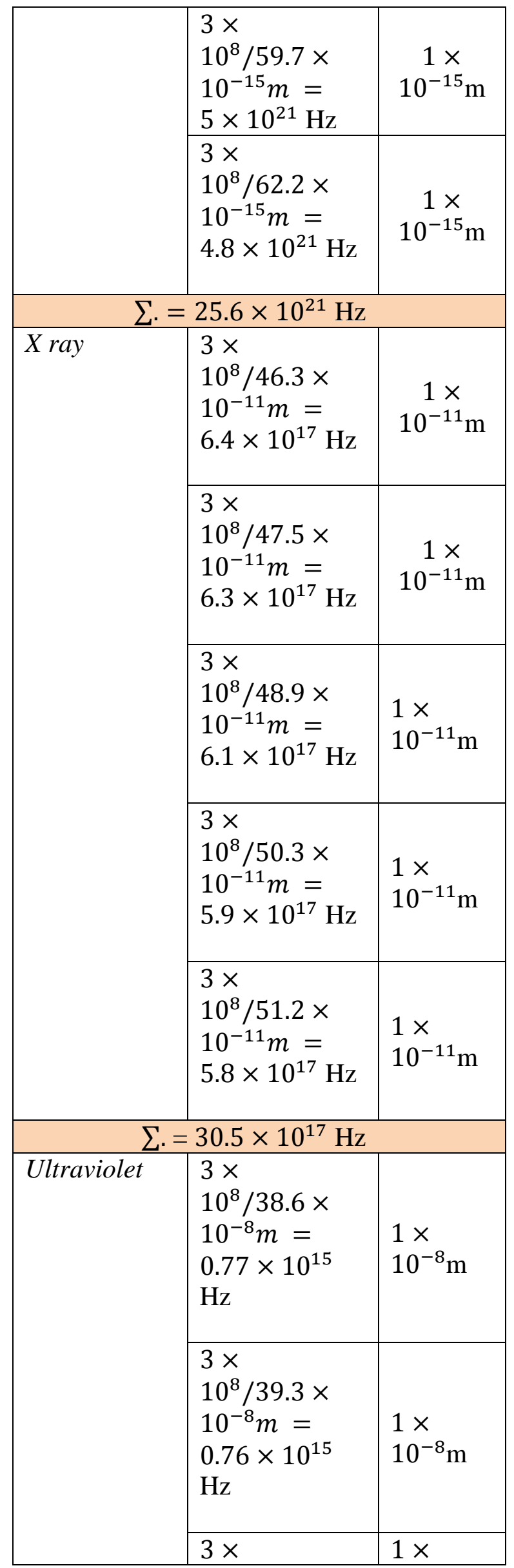




\begin{tabular}{|c|c|c|}
\hline & $\begin{array}{l}10^{8} / 40.8 \times \\
10^{-8} \mathrm{~m}= \\
0.73 \times 10^{15} \\
\mathrm{~Hz}\end{array}$ & $10^{-8} \mathrm{~m}$ \\
\hline & $\begin{array}{l}3 \times \\
10^{8} / 41.5 \times \\
10^{-8} m= \\
0.72 \times 10^{15} \\
\mathrm{~Hz}\end{array}$ & $\begin{array}{l}1 \times \\
10^{-8} \mathrm{~m}\end{array}$ \\
\hline & $\begin{array}{l}3 \times \\
10^{8} / 43.2 \times \\
10^{-8} \mathrm{~m}= \\
0.69 \times 10^{15} \\
\mathrm{~Hz}\end{array}$ & $\begin{array}{l}1 \times \\
10^{-8} \mathrm{~m}\end{array}$ \\
\hline$\sum$. & $3.67 \times 10^{15} \mathrm{~Hz}$ & \\
\hline Visible & $\begin{array}{l}3 \times \\
10^{8} / 122.7 \times \\
10^{-7} \mathrm{~m}= \\
0.24 \times 10^{14} \\
\mathrm{~Hz}\end{array}$ & $\begin{array}{l}32.3 \times \\
3.8 \times \\
10^{-7} \mathrm{~m}\end{array}$ \\
\hline & $\begin{array}{l}3 \times \\
10^{8} / 127.7 \times \\
10^{-6} \mathrm{~m}= \\
0.23 \times 10^{14} \\
\mathrm{~Hz}\end{array}$ & $\begin{array}{l}33.6 \times \\
3.8 \times \\
10^{-7} \mathrm{~m}\end{array}$ \\
\hline & $\begin{array}{l}3 \times \\
10^{8} / 129.96 \times \\
10^{-7} \mathrm{~m}= \\
0.23 \times 10^{14} \\
\mathrm{~Hz}\end{array}$ & $\begin{array}{l}34.2 \times \\
3.8 \times \\
10^{-7} \mathrm{~m}\end{array}$ \\
\hline & $\begin{array}{l}3 \times \\
10^{8} / 134.14 \times \\
10^{-7} \mathrm{~m}= \\
0.22 \times 10^{14} \\
\mathrm{~Hz}\end{array}$ & $\begin{array}{l}35.3 \times \\
3.8 \times \\
10^{-7} \mathrm{~m}\end{array}$ \\
\hline & $\begin{array}{l}3 \times \\
10^{8} / 137.94 \times \\
10^{-7} \mathrm{~m}= \\
0.21 \times 10^{14} \\
\mathrm{~Hz}\end{array}$ & $\begin{array}{l}36.3 \times \\
3.8 \times \\
10^{-7} \mathrm{~m}\end{array}$ \\
\hline$\sum .=$ & $1.13 \times 10^{14} \mathrm{~Hz}$ & \\
\hline Infrared & $\begin{array}{l}3 \times \\
10^{8} / 5.25 \times \\
10^{-3} \mathrm{~m}= \\
0.57 \times 10^{11}\end{array}$ & $\begin{array}{l}17.5 \times \\
0.3 \times \\
10^{-3} \mathrm{~m}\end{array}$ \\
\hline
\end{tabular}




\begin{tabular}{|c|c|c|}
\hline & $\mathrm{Hz}$ & \\
\hline & $\begin{array}{l}3 \times \\
10^{8} / 5.82 \times \\
10^{-3} m= \\
0.51 \times 10^{11} \\
\mathrm{~Hz}\end{array}$ & $\begin{array}{l}19.4 \times \\
0.3 \times \\
10^{-3} \mathrm{~m}\end{array}$ \\
\hline & $\begin{array}{l}3 \times \\
10^{8} / 6.48 \times \\
10^{-3} m= \\
0.46 \times 10^{11} \\
\mathrm{~Hz}\end{array}$ & $\begin{array}{l}21.6 \times \\
0.3 \times \\
10^{-3} \mathrm{~m}\end{array}$ \\
\hline & $\begin{array}{l}3 \times \\
10^{8} / 7.11 \times \\
10^{-3} m= \\
0.42 \times 10^{11} \\
\mathrm{~Hz}\end{array}$ & $\begin{array}{l}23.7 \times \\
0.3 \times \\
10^{-3} \mathrm{~m}\end{array}$ \\
\hline & $\begin{array}{l}3 \times \\
10^{8} / 7.65 \times \\
10^{-3} m= \\
0.39 \times 10^{11} \\
\mathrm{~Hz}\end{array}$ & $\begin{array}{l}25.5 \times \\
0.3 \times \\
10^{-3} \mathrm{~m}\end{array}$ \\
\hline \multicolumn{3}{|c|}{$\sum .=2.35 \times 10^{11} \mathrm{~Hz}$} \\
\hline \multirow[t]{5}{*}{ Microwave } & $\begin{array}{l}3 \times 10^{8} / 5.0 \times \\
10^{-1} \mathrm{~m}= \\
6 \times 10^{8} \mathrm{~Hz}\end{array}$ & $\begin{array}{l}1 \times \\
10^{-1} \mathrm{~m}\end{array}$ \\
\hline & $\begin{array}{l}3 \times 10^{8} / 6.2 \times \\
10^{-1} \mathrm{~m}= \\
4.8 \times 10^{8} \mathrm{~Hz}\end{array}$ & $\begin{array}{l}1 \times \\
10^{-1} \mathrm{~m}\end{array}$ \\
\hline & $\begin{array}{l}3 \times 10^{8} / 7.3 \times \\
10^{-1} \mathrm{~m}= \\
4.1 \times 10^{8} \mathrm{~Hz}\end{array}$ & $\begin{array}{l}1 \times \\
10^{-1} \mathrm{~m}\end{array}$ \\
\hline & $\begin{array}{l}3 \times 10^{8} / 8.4 \times \\
10^{-1} \mathrm{~m}= \\
3.6 \times 10^{8} \mathrm{~Hz}\end{array}$ & $\begin{array}{l}1 \times \\
10^{-1} \mathrm{~m}\end{array}$ \\
\hline & $\begin{array}{l}3 \times 10^{8} / 9.5 \times \\
10^{-1} \mathrm{~m}= \\
3.2 \times 10^{8} \mathrm{~Hz}\end{array}$ & $\begin{array}{l}1 \times \\
10^{-1} \mathrm{~m}\end{array}$ \\
\hline \multicolumn{3}{|c|}{$\sum .=21.7 \times 10^{8} \mathrm{~Hz}$} \\
\hline \multirow[t]{4}{*}{ Radio } & $\begin{array}{l}3 \times \\
10^{8} / 0.8 \mathrm{~m}= \\
3.75 \times 10^{7} \mathrm{~Hz}\end{array}$ & $10 m$ \\
\hline & $\begin{array}{l}3 \times \\
10^{8} / 1.3 m= \\
2.3 \times 10^{7} \mathrm{~Hz}\end{array}$ & $10 m$ \\
\hline & $\begin{array}{l}3 \times \\
10^{8} / 1.8 m= \\
1.67 \times 10^{7} \mathrm{~Hz}\end{array}$ & $10 m$ \\
\hline & $3 \times$ & $10 m$ \\
\hline
\end{tabular}




\begin{tabular}{|l|l|l|}
\hline & $10^{8} / 2.2 \mathrm{~m}=$ & \\
$1.36 \times 10^{7} \mathrm{~Hz}$ & \\
\cline { 2 - 3 } & $3 \times$ & \\
& $10^{8} / 3.2 \mathrm{~m}=$ & $10 \mathrm{~m}$ \\
$0.94 \times 10^{7} \mathrm{~Hz}$ & \\
\hline$\sum .=10.02 \times 10^{7} \mathrm{~Hz}$ & \\
\hline
\end{tabular}

Tabel 2. Data hasil pengukuran frekuensi spektrum elektromagnetik

\begin{tabular}{|l|l|}
\hline $\begin{array}{c}\text { Spektrum } \\
\text { Elektromagnetik }\end{array}$ & \multicolumn{1}{|c|}{ Hasil Pengukuran } \\
\hline Gamma ray & $\begin{array}{l}\left(5.08 \times 10^{21} \pm 1.97 \%\right) \\
\mathrm{Hz}\end{array}$ \\
\hline X ray & $\begin{array}{l}\left(6.1 \times 10^{17} \pm 1.97 \%\right) \\
\mathrm{Hz}\end{array}$ \\
\hline Ultraviolet ray & $\left(0.73 \times 10^{15} \pm 2.18 \%\right)$ \\
& $\mathrm{Hz}$ \\
\hline Visible & $\left(0.23 \times 10^{14} \pm 2.65 \%\right)$ \\
& $\mathrm{Hz}$ \\
\hline Infrared & $\left(0.47 \times 10^{11} \pm 7.66 \%\right)$ \\
& $\mathrm{Hz}$ \\
\hline Microwave & $\left(4.34 \times 10^{8} \pm 12.90 \%\right)$ \\
& $\mathrm{Hz}$ \\
\hline Radio & $\left(2 \times 10^{7} \pm 28.04 \%\right) \mathrm{Hz}$ \\
\hline
\end{tabular}

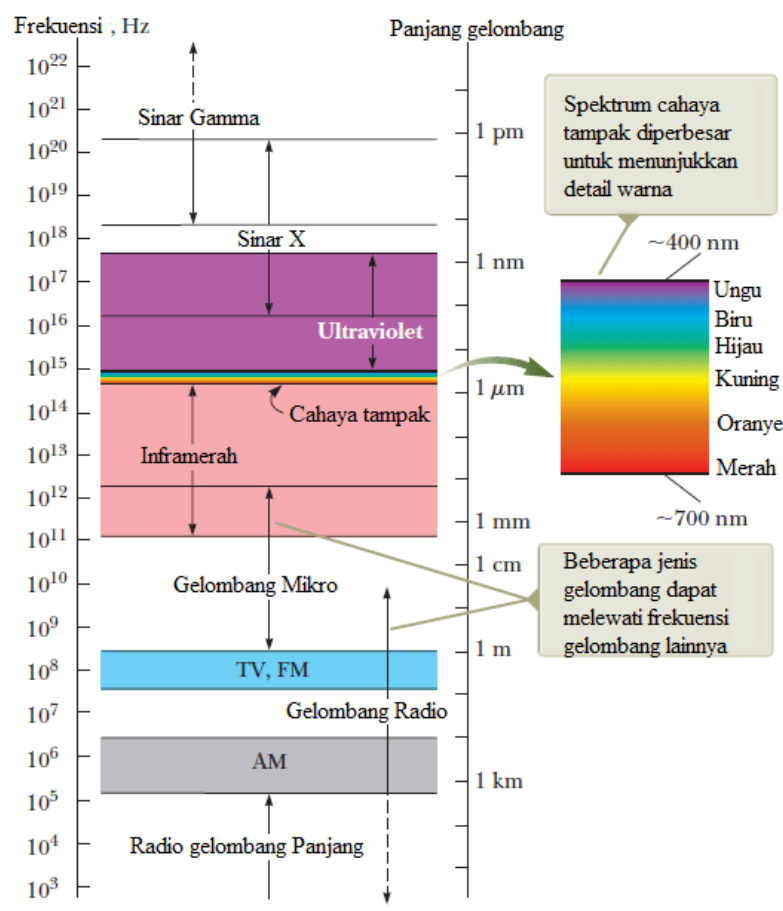

Gambar 3. Rentang spektrum elektromagnetik 
Dari eksperimen tersebut dihasilkan bahwa semakin besar nilai frekuensi maka nilai panjang gelombangnya akan semakin kecil. Hal tersebut sesuai dengan persamaan hubungan antara kecepatan cahaya/elektromagnetik, frekuensi dengan panjang gelombang. Dimana frekuensi berbanding terbalik dengan panjang gelombang. Lalu, kami membandingkan hasil pengukuran spektrum gelombang elektromagnetik pada tabel 3 dengan rentang frekuensi dan panjang gelombang spektrum elektromagetik pada gambar 3. Terdapat kesesuaian antara hasil pengukuran pada tabel 3 dengan rentang spektrum elektromagnetik pada gambar 3 . Dengan nilai KTP relatif hasil pengukuran yang terendah pada sinar gamma dan sinar X yang bernilai $1.97 \%$, sedangkan KTP relatif terbesar pada gelombang radio yang bernilai 28.04\%. KTP relatif yang bernilai besar pada infrared, gelombang mikro dan gelombang radio dapat disebabkan oleh kesalahan paralak dari pengamat.

Melalui hasil perhitungan ternyata frekuensi elektromagnetik berbanding terbalik dengan panjang gelombang sesuai dengan persamaan matematis nya yaitu,

$$
f \approx \frac{1}{\lambda}
$$

Semakin besar nilai frekuensi maka semakin kecil nilai panjang gelombang. Begitu pun sebaliknya semakin besar nilai panjang gelombang maka semakin kecil nilai frekuensi. Apabila diurutkan spektrum elektromagnetik dari panjang gelombang terbesar yaitu gelombang radio, gelombang mikro, infrared, cahaya tampak, sinar ultraviolet, sinar $\mathrm{X}$ dan sinar gamma. Dan jika berdasarkan frekuensinya yaitu sinar gamma, sinar X, sinar ultraviolet, cahaya tampak, infrared, gelombang mikro dan gelombang radio.

Penelitian ini didukung dengan studi literatur tentang penerapan gelombang elektromagnetik dengan memanfaatkan panjang gelombangnya ataupun frekuensinya dalam kehidupan sehari-hari seperti pada gambar dibawah ini.
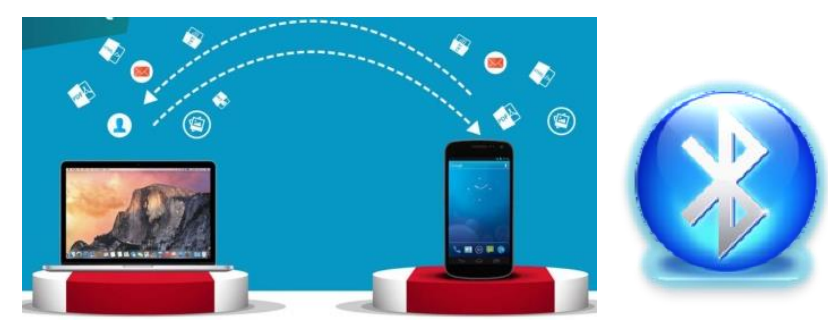

Gambar 4. Bluetooth untuk mengirim data 

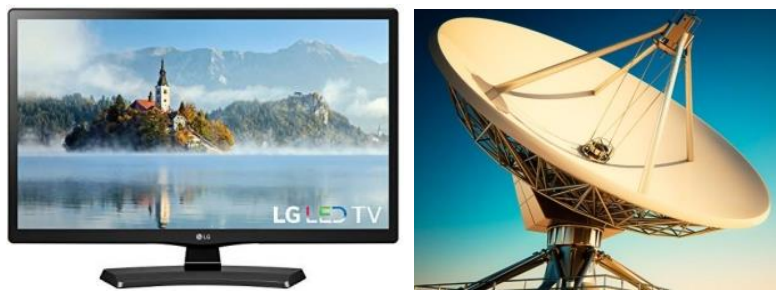

Gambar 5. TV dan Pemancar TV

\begin{tabular}{|lr|l|}
\hline \multicolumn{2}{|l|}{ Bluetooth memiliki } & Pemancar r TV \\
Frekuensi \pm 2.4 & memiliki Frekuensi \\
$\mathrm{GHz}$ dan panjang & $\pm 210 \mathrm{MHz}$ dan \\
gelombang \pm 12.5 & panjang gelombang \\
$\mathrm{cm}, \quad$ termasuk & $\pm 140 \mathrm{~cm}$, termasuk \\
gelombang radio & gelombang radio \\
\hline
\end{tabular}

Bluetooth menjadi salah satu wireless yang dapat dimanfaatkan untuk pengiriman data melalui gelombang elektromagnetik. Bluetooth yang paling popular adalah dalam ponsel sebagai transmisi data. Bluetooth juga memiliki daya media gelombang elektromagnetik atau radio yang rendah sehingga tidak mengganggu peralatan lain yang menggunakan elektromagnetik juga guna meminimalisir intereperensi gelombang yang dapat mengganggu satu sama lain. Dengan menggunakan gelombang radio yang memiliki frekuensi yang lebih rendah dibandingkan spektrum yang lain dan panjang gelombang yang besar dimanfaatkan untuk transmisi data.

Sedangkan pemancar TV Secara prinsip tidaklah berbeda dengan pemancar radio, hanya pada pemancar televisi sinyal informasi yang dipancarkan berupa sinyal gambar (video) dan suara (audio). Dengan menggunakan gelombang elektromagnetik arus informasi menjadi mudah didapatkan dengan cepat.

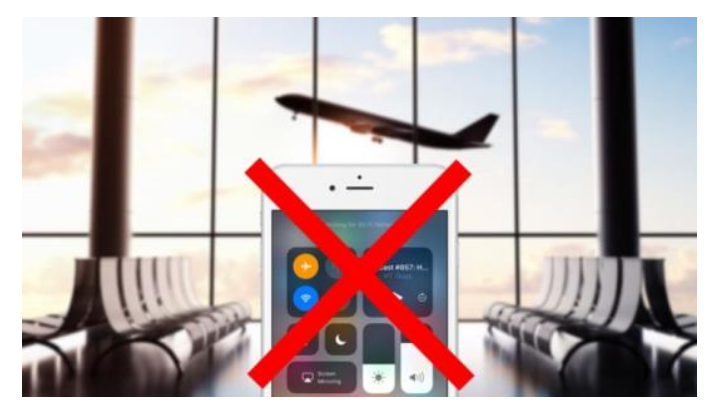

Gambar 6. Dilarang mengaktifkan smartphone dalam pesawat 
Beberapa tempat handphone dilarang diaktifkan salah satunya yaitu di dalam pesawat, ini di karenakan gelombang yang dikeluarkan handphone dapat mengganggu jalinan komunikasi pesawat yang dapat berakibat fatal. Karena selama penerbangan pilot terus terhubung dengan aircontrol didarat dan memperhatikan radar. Komunikasi aircontrol dan radar ini menggunakan gelombang radio, sehingga gelombang elektromagnetik akan mengganggu komunikasi pilot dan pilot akan mendapatkan gangguan di jalur komunikasinya atau gambar yang mengganggu diradar. Maka dari itu, pramugari akan meminta penumpang untuk mematikan alat komunikasinya demi keselamatan perjalanan. Hal ini menunjukkan selain pemanfaatannya yang sangat berdampak besar terhadap kehidupan manusia, gelombang elektromagnetik juga harus digunakan dengan bijak dan sesuai dengan aturan guna mencegah dampak negatif yang lebih besar.

Dari studi pustaka ini kita dapat mengetahui penerapan gelombang elektromagnetik dalam kehidupan, ternyata penggunaan gelombang elektromagnetik sangat dekat disekitar kita. Bluetooth yang berfungsi untuk mengirim data berupa foto, video dan sebagainya menggunakan gelombang radio begitu pula pemancar TV yang menggunakan gelombang radio untuk mengirim data dan menampilkan gambar dan suara serta menjadikan arus informasi yang berjalan dengan cepat. Dengan mengetahui frekuensi gelombang radio yang digunakan Bluetooth kita dapat mengetahui panjang gelombang dari gelombang tersebut. Bahkan handphone yang menjadi benda yang tidak lepas dari kita juga menggunakan gelombang elektromagnetik yaitu gelombang radio untuk mengirim data berupa Bluetooth sebagai salah satu fiturnya.

Melalui penelitian ini kita dapat mengetahui besar frekuensi spektrum elektromagnetik dan mengetahui penerapannya dengan manfaatkan baik frekuensinya ataupuan panjang gelombang suatu spektrum elektromagnetik dalam teknologi untuk mempermudah aktivitas manusia dan dapat melihat secara nyata manfaat dari spektrum elektromagnetik

\section{Simpulan}

Kesimpulan yang diambil dari penelitian ini yaitu semakin besar nilai frekuensi gelombang elektromagnetik maka semakin kecil nilai panjang gelombang elektromagnetik. Karena secara matematis frekuensi berbanding terbalik dengan panjang gelombang. Dan penerapan spektrum elektromagnetik dengan memanfaatkan panjang gelombang atau 
frekuensinya dapat banyak kita temui secara nyata dalam kehidupan sehari-hari sebagai pembelajaran.

\section{Referensi}

Fitriyah. (2018). Analisis Pemahaman Konsep Spektrum Gelombang Elektromagnetik Pada Siswa SMA Kelas 12 Di Kabupaten Bondowoso. Seminar Nasional Pendidikan Fisika 2018, Vol. 3, 11 Maret 2018.

Nana. (2018). Implementasi Model POE2WE Dengan Pendekatan Saintifik Dalam Pembelajaran Gerak Lurus Di SMA. Prosiding SNPS, Surakarta 27 Oktober 2018.

Nana. (2014). The Development Of Predict, Observe, Explain, Elaborate, Write, and Evaluate (Poe2we) Learning Model in Physics Learning At Senior Secondary School. Journal of Education and Practice, Vol. 5, No. 19, 2014, ISSN 2222-1735

Sutarto. (2005). Buku Ajar Fisika (BAF) dengan Tugas Analisis Foto Kejadian Fisika (AFKF) sebagai Alat Bantu Penugasaan Konsep Fisika. Jurnal Pendidikan dan Kebudayaan No, 54, tahun ke-11, Mei 2005.

Surjono, H. (1996). Eskperimen Pengiriman Sinyal Televisi Dengan Pemancar TV dan CCTV Serta Pemanfaatannya Dalam Pendidikan. Journal PTK. No. 9 (VII): 35-43.

Timor, Agus R. (2016). Analisis Gelombang Elektromagnetik Dan Seismik Yang Ditimbulkan Oleh Gejala Gempa. Jurnal Nasional Teknik Elektro, Vol: 5, No. 3, November 2016. 
